\title{
The adaptation of mechanically softened gutta-percha to the canal walls in the presence or absence of smear layer: a scanning electron microscopic study
}

\author{
A. PALLARÉS \& V. FAUS \\ Department of Pathology and Dental Therapeutics, Faculty of Odontology, University of Valencia, Valencia. Spain \\ G. N. GLICKMAN \\ Department of Cariology, Restorative Sciences, and Endodontics, School of Dentistry. University of Michigan, Ann Arbor, \\ Michigan, USA
}

\section{Summary}

The objective of this study was to compare the adaptation of mechanically softened gutta-percha to the root canal wall in the presence and absence of smear layer. The root canals of 20 freshly extracted human maxillary incisors were cleaned and shaped. Prior to obturation. 10 root canals were irrigated with $20 \mathrm{ml}$ of $50 \%$ citric acid followed by $20 \mathrm{ml}$ of $5.25 \%$ sodium hypochlorite. All canals were obturated with mechanical compaction of gutta-percha and AH-26 sealer. After $72 \mathrm{~h}$, each tooth was fractured in half. Scanning electron microscopy demonstrated that the sealer had formed a continuous layer in contact with the canal walls. becoming progressively thinner towards the apex. The sealler penetrated into the dentinal tubules along with projections of gutta- percha only in those teeth without smear layer.

Keywords: mechanically softened gutta-percha, root canal obturation, smear layer

\section{Introduction}

McComb \& Smith (1975) observed that the smear layer on the dentinal walls of biomechanically instrumented root canals occluded the dentinal tubules. Wayman et al. (1979) and Berg et al. (1986) suggested that the smear layer could prevent the penetration of obturating materials into the tubules. The presence of smear layer was also proposed as a potential substrate for bacterial growth (Pitt Ford \& Roberts 1990). Yamada et al. (1983)

Correspondence: Gerald N. Glickman. Department of Cariology. Restorative Sciences, and Endodontics, School of Dentistry, University of Michigan, 1011 N. University, Ann, Arbor, Michigan 48109, USA. noted that a final canal irrigation with $10 \mathrm{ml}$ EDTA followed by $10 \mathrm{ml}$ of $5.25 \%$ sodium hypochlorite was effective in removing the smear layer, thus rendering the dentinal tubules more permeable. Others have observed a similar effect with a final irrigation of $20 \mathrm{ml}$ of $50 \%$ citric acid followed by $20 \mathrm{ml}$ of $5.25 \%$ sodium hypochlorite (Baumgartner et al. 1984, Ferrer 1992).

The lack of a three-dimensional obturation of the root canal system has been cited as one of the major causes of failure in endodontic treatment (Ingle \& Bakland 1994). In recent years, alternative methods of obturation using thermoplasticized gutta-percha or mechanically softened gutta-percha have been developed to provide a more rapid and perhaps more effective means of filling root canals three-dimensionally.

JS Quick-fillTM (JS Dental, Ridgefield, CT, USA) is a root canal obturation system consisting of a sized titanium transporter that has been coated with gutta-percha. The transporter is attached to a slow-speed handpiece, and when introduced and rotated into the prepared root canal, the gutta-percha is mechanically softened because of the frictional heat that is generated.

The purpose of this study was to compare the adaptation of mechanically softened gutta-percha (JS QuickfillTM) and cement sealer (AH-26) to the dentinal walls of prepared root canals in the presence and absence of smear layer.

\section{Materials and methods}

Twenty freshly extracted human maxillary incisors were stored in water. Endodontic access cavities were made using a high-speed handpiece. Working length was determined by inserting a size $10 \mathrm{~K}$-file until it was visible at the apical foramen and withdrawing it $0.5 \mathrm{~mm}$. 
All canals were prepared with K-type files to a master file size $40,0.5 \mathrm{~mm}$ short of the radiographic apex. Three millilitres of $5.25 \%$ sodium hypochlorite (NaOCI) were used as the intracanal irrigant after each instrument. All irrigating solutions were delivered via a 23 -gauge needle inserted as far as possible into the canal without binding. Final shaping of the canals was accomplished using a step-back technique in 1-mm increments with Hedstrom files to a final size 70 . Twenty millilitres of $5.25 \% \mathrm{NaOCI}$ were used as a final flush. All canals were dried using paper points. The teeth were randomly divided into two groups:

(1) Group I (with smear layer): In 10 incisors, $\mathrm{AH} 26$ silver-free (DeTrey, Konstanz, Germany) was introduced with a size 35 file, and the canals were subsequently obturated with a JS Quick-fill ${ }^{\mathrm{M} M}$ two sizes smaller than the master file used (in accordance with the manufacturer's guidelines).

(2) Group II (without smear layer): In the remaining 10 incisors, the smear layer was removed with a final irrigation of $20 \mathrm{ml}$ of $50 \%$ citric acid followed by $20 \mathrm{ml}$ of $5.25 \%$ sodium hypochlorite. The canals were dried with paper points. $\mathrm{AH} 26$ was introduced with a size 35 file, and the canals were subsequently obturated with a IS Quick-fillTM two sizes smaller than the master file used.

In both groups, the JS Quick-fillTM was rotated clockwise at a speed of $4500 \mathrm{rpm}$ using a slow-speed handpiece. In all cases, the titanium carrier was withdrawn from the canal while rotation continued.

Following obturation, all teeth were stored in water for $72 \mathrm{~h}$. After this period, the teeth were grooved using a disc at slow speed and fractured into two halves with pliers. The halves were dehydrated via critical point drying, and subsequently sputter-coated in gold and evaluated under the scanning electron microscope (SEM) (Hitachi S-4100, Tokyo, Japan) at various magnifications.

\section{Results}

The cement sealer was located adjacent to the dentinal walls in all of the specimens. The sealer did not appear to be embedded within the gutta-percha and seemed to form a layer which became progressively thinner; the cement was thicker in the coronal third (Fig. 1). and thinner $(7-8 \mu \mathrm{m}$ thick) towards the apical third (Fig. 2).

Neither the gutta-percha nor root canal sealer penetrated the dentinal tubules of the root canals with the smear layer. The gutta-percha surface exhibited a

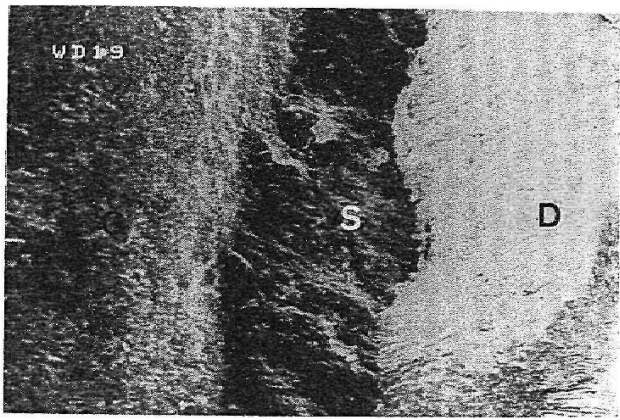

Fig. 1. The coronal third: sealer (s) thickness. $150 \mu \mathrm{m}$ between dentin (d) and gutta-percha $(\mathrm{g})$ (original magnification, $\times 200$ ).

wave-like appearance in a direction opposite to the axis of rotation (Fig. 3); this was apparently caused by the rubbing or frictional action of the gutta-percha against the canal walls with subsequent softening of the guttapercha.

The sealer penetrated the dentinal tubules of those root canals which had the smear layer removed. In all cases, the penetrating sealer emanated from the surface layer of sealer. Depth of penetration varied from 10 to $15 \mu \mathrm{m}$ in most cases. However, in one particular case. a depth of $60 \mu \mathrm{m}$ was observed. Surface protuberances were evident from the gutta-percha surface because of the entry of the material into the dentinal tubules (Fig. 4).

In some areas of the canal, there were spaces between the gutta-percha and cement sealer (Fig. 5). Since the irregularities of the dentinal wall were well reproduced on the gutta-percha, these spaces were possibly artifacts caused during specimen exposure to vacuum during SEM examination (Zmener \& Gimenes Frias 1991).

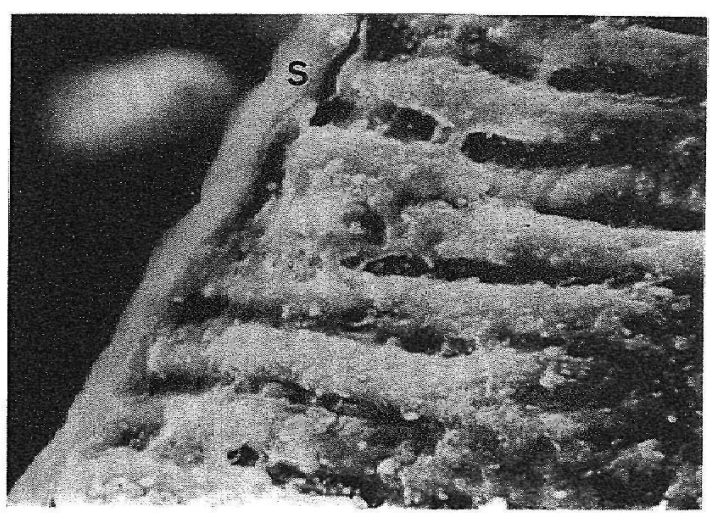

Fig. 2. The apical third: sealer thickness. $8-10 \mu \mathrm{m}$. Sealer has penetrated the dentinal tubules foriginal magnification, $\times 2500$ ). 


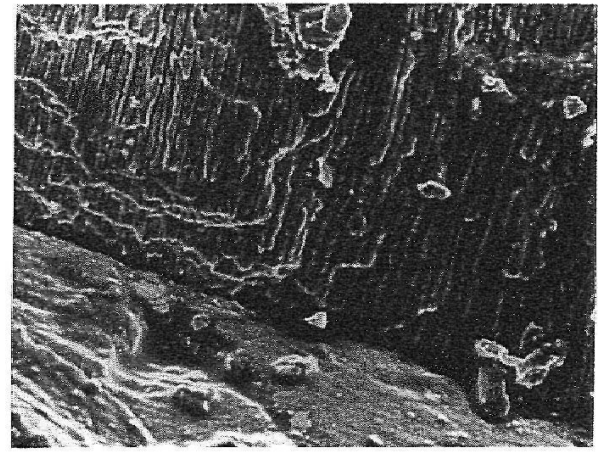

Fig. 3 The wave-like appearance of the gutta-percha surface in root canals with smear layer. Sealer cannot be detected within the tubules.

Another possible explanation for these spaces may be related to a potentially weak union interface between the gutta-percha and sealer. When a specimen is fractured in halves, the interface could be an area where cracking occurs. In some cases, gutta-percha was trapped in the coronal canal in one root segment during fracturing but remained in the apical canal in the complementary root segment. This phenomenon could have also explained the artifactual cracks between sealer and gutta-percha.

\section{Discussion}

An unexpected finding was related to the distribution of the AH-26 sealer: in all the specimens, the sealer was found to be in intimate contact with the canal walls and did not appear to be embedded in the mass of guttapercha. This may be explained by the nature of the kinetic energy that was generated during the rotational

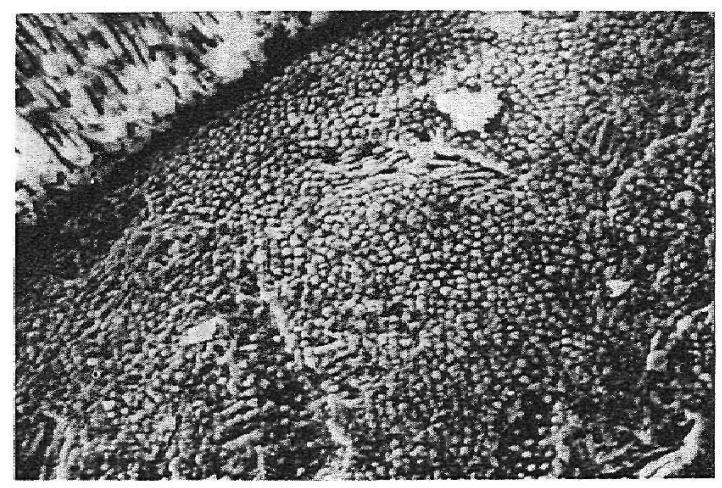

Fig. 4 The pointed appearance of the gutta-percha surface which had been in contact with the canal walls in teeth without smear layer.

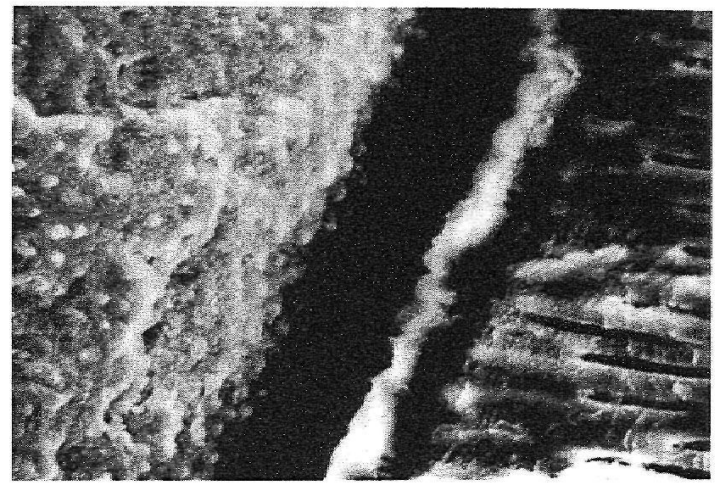

Fig. 5 Cracks between sealer and gutta-percha can be observed in some areas.

movement of the instrument within the canal, centrifugally pushing sealer particles to the periphery of the dentinal wall. This could have also aided the penetration of the cement sealer into the tubules of canals without the smear layer.

Mader et al. (1984) observed that, because of the impulsion-traction movements that occur during root canal instrumentation, the particulate smear layer can penetrate up to $40 \mu \mathrm{m}$ into the dentinal tubules. In the present study, penetrations of up to $60 \mu \mathrm{m}$ were observed with the cement sealer. Although Abramovich \& Goldberg (1976) reported a poor penetration of AH-26 into the tubules, the presence of smear layer was not considered. Oksan et al. (1993) also noted that the presence of smear layer impeded the cement sealer from entering the tubules. They also stated that the physical and chemical properties of a cement sealer could limit its penetration even in the absence of smear layer. The present study suggests that rotational movements could be an additional factor that could affect sealer penetration.

In those teeth without smear layer, protuberances and indentations of the gutta-percha were observed where the material had been in close contact with the tubules. This phenomenon was also observed by Gutmann (1993) during his evaluation of high temperature, heat-softened gutta-percha in the absence of smear layer. Gencoglu et al. (1993) also confirmed this finding in their study of low-temperature heat-softend guttapercha and Thermafil.

In some cases, spaces were observed between the gutta-percha and cement sealer. These could have been caused by the contraction of the gutta-percha upon cooling or vacuum exposure during SEM. However, this finding could have also been attributed to a procedural 
retraction that was exerted on the gutta-percha when the teeth were fractured.

\section{Conclusions}

The results of this study demonstrated a better mechanical adaptation of mechanically softened gutta-percha to the walls of the canal when the smear layer was removed. In these teeth, the cement sealer formed a layer between the gutta-percha and the canal walls, penetrating several microns into the dentinal tubules.

\section{References}

Abramovich A, GoLDBERG F (1976) The relationship of the root canal sealer to the dentine wall. An in vitro study using the scanning electron microscope. Journal of the British Endodontic Society 9,81-6.

Baumgartner JC, Brown CM, Mader Cl, Peters DD, Shulman jD (1984) A scanning electron microscopic evaluation of root canal debridement using saline, sodium hypochlorite, and citric acid. Journal of Endodontics 10,525-31.

Berg MS, Jacobsen EL, Begole EA. Remeikis NA (1986) A comparison of five irrigating solutions: a scanning electron microscopic study. Joumal of Endodontics 12, $192-7$.

FER RER CM (1992) Estudio del area de difusion dentinaria en la preparacion biomecánica de conductos radiculares. Tesis Doctoral. Facultad de
Odontologia, Universidad de Granada, Granada, Spain.

GenCOGLU N, SAMANI S, GÚNDAY M (1993) Dentinal wall adaptation of thermoplasticized gutta-percha in the presence or absence of smear layer: a scanning electron microscope study. Journal of Endodontics 19, 558-62.

GUTMANN JL (1993) Adaptation of injected thermoplasticized gutta percha in the absence of the dentinal smear laver. International Endodontic Journal 26,87-92.

INGLE JI, BAKLAND LK (1994) Endodontics, 4th edn. Philadelphia, PA: Williams \& Wilkins.

McComв D. SмlTH DC (1975) A preliminary scanning electron microscopic study of root canals after endodontic procedures. Journal of Endodontics 1, 238-42.

Mader CL, Baumgartner JC, Peters DD (1984) Scanning electron microscopic investigation of the smeared layer on root canal walls. Journal of Endodontics 10,477-83.

OKSAN T. AKTENER BO. SEN BH, TEZEL H (1993) The penetration of root canal sealers into dentinal tubules. A scanning electron microscopic study. International Endodontic Journal 26, 301-5.

Pitt Ford TR, Roberts GJ (1990) Tissue response to glass ionomer retrograde root fillings. International Endodontic journal 23. 233-8.

Wayman BE, Kopp WM. Pinero G], LAzZari EP (1979) Citric and lactic acids as root canal irrigants in vitro. Journal of Endodontics $\mathbf{5}$. $258-65$.

YAMADA R, ARMAS A. GOLDMAN M. LIN PS (1983) A scanning electron microscopic comparison of a high volume final flush with several irrigation solutions: part 3. Joumal of Endodontics 9.137-42.

ZMEner O, Gimenes Frias J (1991) Thermomechanical compaction of gutta-percha: a scanning electron microscope study. Endodontics and Dental Traumatology $7.153-7$. 
This document is a scanned copy of a printed document. No warranty is given about the accuracy of the copy. Users should refer to the original published version of the material. 